\title{
Inhibition of Synthesis of Fetal Hemoglobin by an Isoleucine Analogue*
}

\author{
George R. Honig \\ (From the Department of Pediatrics, University of Illinois College of Medicine, \\ Chicago, Illinois)
}

\begin{abstract}
Reticulocytes from newborn infants with $\mathrm{Rh}$ isoimmune hemolytic disease actively incorporated radioactive amino acids in vitro into hemoglobins F and A. Approximately $50 \%$ of the reticulocytes appeared capable of synthesis of both of these hemoglobins within the same cell, as demonstrated by the selective elution technique of Betke and Kleihauer. An isoleucine analogue, L-O-methylthreonine, inhibited the incorporation of a variety of amino acids into hemoglobin $\mathrm{F}$, without significantly affecting the synthesis of hemoglobin A. The inhibition was prevented upon concomitant addition of L-isoleucine to the medium. These observations suggest that an independent biosynthetic apparatus is present in the cell for the synthesis of each of these two hemoglobins. Because isoleucine is present only in the gamma chains of hemoglobin $F$, the inhibitory effect of the analogue on the synthesis of this hemoglobin must represent a selective effect on the production of gamma chains.
\end{abstract}

\section{Introduction}

The thalassemias are a diverse group of familial anemias which share as a common feature the defective synthesis of globin chains of hemoglobin (1). The hemoglobin produced in these disorders has no apparent structural abnormality (2) and the defect appears to manifest itself as a quantitative diminution in globin-chain production. Impairment of alpha-chain synthesis, which occurs in alpha thalassemia ( 3 ), is associated with abnormal production of Bart's hemoglobin $\left(\gamma_{4}\right)$, hemoglobin

* Received for publication 19 May 1967 and in revised form 14 July 1967.

Supported by a graduate training grant (5 TO1 AM 05344) from the National Institute of Arthritis and Metabolic Diseases, and a grant (RG HD 00568) from the National Institute of Child Health and Human Development, National Institutes of Health, U. S. Public Health Service.

$\ddagger$ U. S. Public Health Service Graduate Trainee in Pediatric Hematology (5 TO1 AM 05344), National Institute of Arthritis and Metabolic Diseases, University of Illinois College of Medicine.

Address requests for reprints to Dr. George R. Honig, Department of Pediatrics, University of Illinois College of Medicine, 840 S. Wood Street, Chicago, I1l. 60612.
$\mathrm{H}\left(\beta_{4}\right)$, and hemoglobin $\delta_{4}$, which do not contain alpha-globin chains (1). In the beta thalassemias, the effect of the biosynthetic defect is a suppression of production of the beta-globin chains of adult hemoglobin (3), and a characteristic, often extreme increase in the nonbeta-chain hemoglobins $F$ and $\mathrm{A}_{2}$ occurs. In the beta thalassemias, however, appreciable amounts of soluble alpha chains do not accumulate, despite a severe defect in betachain production (4). The significance of these associated effects is not understood, although it has been suggested that they may reflect control mechanisms which operate at the level of regulation of gene action (5) or a coordinated mechanism which regulates globin-chain synthesis on the ribosomes (6).

In order to examine the operation of some of the regulatory mechanisms, we performed the present studies to develop an experimental model in which a controlled thalassemia-like lesion could be produced. For this purpose, we took advantage of the unique presence of isoleucine in the gamma chains of hemoglobin $F$. Experiments in vitro using erythroid cells from human cord blood (7) or rabbit reticulocytes (8) with isoleucine-deficient 
media have not demonstrated significant inhibition of hemoglobin synthesis, despite the presence of isoleucine in their respective hemoglobins. In our present study the effect of isoleucine deprivation was augmented by the addition of L-O-methylthreonine, an inhibitor of protein synthesis which is an analogue of isoleucine (9).

\section{Methods}

Incubation procedure. Blood was obtained from newborn infants with isoimmune hemolytic disease due to $\mathrm{Rh}$ incompatibility. The initial $30-50 \mathrm{ml}$ of blood removed at exchange transfusion, which contained small amounts of transfused donor blood, was anticoagulated with heparin and chilled; experiments were begun within $2 \mathrm{hr}$ after collection. We centrifuged the blood at $5000 \mathrm{~g}$ for $15 \mathrm{~min}$ at $4^{\circ} \mathrm{C}$ and removed the plasma without disturbing the buffy coat. Then we washed the cells twice at $4^{\circ} \mathrm{C}$ with an isotonic saline solution (sodium chloride 0.140 mole/liter, potassium chloride 0.005 mole/liter, magnesium chloride $0.0015 \mathrm{~mole} / \mathrm{liter}$ ). The washed cells were suspended in an equal volume of the saline solution and filtered through several layers of gauze.

Incubations were carried out at $37^{\circ} \mathrm{C}$ in $25-\mathrm{ml}$ Ehrlenmeyer flasks open to room air. Each flask contained 1 $\mathrm{ml}$ of cells in a total volume of $10 \mathrm{ml}$. The incubation medium contained sodium chloride, $0.140 \mathrm{~mole} / \mathrm{liter}$; potassium chloride, 0.005 mole/liter; magnesium chloride, 0.0015 mole/liter; Tris-HCl, $\mathrm{pH}$ 7.4, 0.005 mole/liter; glucose, $1 \mathrm{mg} / \mathrm{ml}$; ferrous ammonium sulfate, 0.0001 mole/liter; human transferrin, ${ }^{1} 0.05 \mathrm{mg} / \mathrm{ml}$; and a mixture of amino acids as described by Lingrel and Borsook (10). Isoleucine was omitted except when indicated. Radioactive amino acids equivalent to $5 \mu \mathrm{c}$ of the $\mathrm{L}$-form were added to each flask; the corresponding nonradioactive amino acid was omitted. The radioactive amino acids were purchased from New England Nuclear Corporation (Boston, Mass.) and had the following specific activities: L-arginine- $\mathrm{U}^{14} \mathrm{C}$, (uniformly labeled), 234 $\mathrm{mc} / \mathrm{mmole}$; DL-histidine-2 ${ }^{14} \mathrm{C}, 1.49 \mathrm{mc} / \mathrm{mmole}$; L-isoleucine-U- ${ }^{14} \mathrm{C}, 275 \mathrm{mc} / \mathrm{mmole}$; L-leucine- $1-{ }^{14} \mathrm{C}, 34.1 \mathrm{mc} /$ mmole; DL-lysine- $1-{ }^{14} \mathrm{C}, 3.66 \mathrm{mc} / \mathrm{mmole}$; and $\mathrm{L}$-valine-1${ }^{14} \mathrm{C}, 22 \mathrm{mc} / \mathrm{mmole}$. When $\mathrm{L}-\mathrm{O}$-methylthreonine was added, it was at a final concentration of 25 mmoles/liter.

Separation of hemoglobins. Incubation periods were terminated by rapid chilling of the flasks in an ice water mixture. The cells were washed twice with the isotonic saline solution at $4^{\circ} \mathrm{C}$, and the erythrocytes lysed by the addition of 4 volumes of cold magnesium chloride,

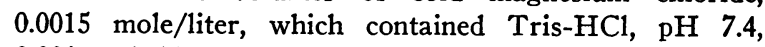
$0.001 \mathrm{~mole} / \mathrm{liter}$; after $45 \mathrm{sec} 1.7 \mathrm{M}$ sodium chloride was added to bring the solution rapidly to isotonicity. The lysates were saturated with carbon monoxide and centrifuged at $7000 \mathrm{~g}$ for $15 \mathrm{~min}$ at $4^{\circ} \mathrm{C}$. The supernatants were further centrifuged at $100,000 \mathrm{~g}$ for $90 \mathrm{~min}$; the

1 Pentex, Inc., Kankakee, Ill. clarified solutions were decanted, saturated with carbon monoxide, and frozen at $-20^{\circ} \mathrm{C}$ until further fractionated.

Hemoglobins $\mathrm{F}$ and $\mathrm{A}$ were separated by the chromatographic method of Zade-Oppen (11) with minor modification. Columns of Sephadex G-25, $1 \times 30 \mathrm{~cm}$, were equilibrated with $0.05 \mathrm{M}$ sodium phosphate, $\mathrm{pH}$ 6.0, which was saturated with carbon monoxide. From 1.0 to $2.5 \mathrm{ml}$ of the lysates, containing $45-60 \mathrm{mg}$ of hemoglobin, was applied to the columns and eluted with the same buffer over a $30 \mathrm{~min}$ period. The eluates were applied to columns of Sephadex CM-C 50, $2 \times 5 \mathrm{~cm}$, which had been equilibrated with $50 \mathrm{~mm}$ phosphate buffer, $\mathrm{pH}$ 6.0. The columns were first eluted with $100 \mathrm{ml}$ of the starting buffer, during which time the hemoglobin band remained within 3-4 $\mathrm{mm}$ of the top of the column. The effluents contained small amounts of protein having variable, sometimes high specific activities (Fig. 1). Further elution was performed with increasing concentrations of sodium chloride. The first hemoglobin peak was eluted with $250-400$ $\mathrm{ml}$ of buffer containing $0.05 \mathrm{~m}$ sodium phosphate, $\mathrm{pH} 6.0$, and $0.050 \mathrm{~m}$ sodium chloride. The remainder of the hemoglobin, which was retained within the upper $1-2 \mathrm{~cm}$ of the column, was then eluted with buffer containing $0.110 \mathrm{M}$ sodium chloride. In some experiments this peak was eluted with $0.50 \mathrm{~m}$ sodium phosphate, $\mathrm{pH}$ 7.0. Chromatography was carried out at room temperature with an elution rate of $0.5-0.7 \mathrm{ml} / \mathrm{min}$.

The completeness of the hemoglobin separation obtained by this method was demonstrated with the use of radioactive hemoglobins. Incubation of cells with leucine- ${ }^{14} \mathrm{C}$ resulted in the labeling of both of the hemoglobin peaks (Fig. 1a). Radioactivity derived from isoleucine, which is not present in hemoglobin A (12), labeled only the first hemoglobin peak (Fig. $1 b$ ), demonstrating that the fetal hemoglobin was confined to the first hemoglobin peak. In another experiment nonradioactive lysate from a newborn infant was mixed with ${ }^{50} \mathrm{Fe}$ labeled hemoglobin obtained from an adult who was undergoing ferrokinetic studies. After chromatography, $97.3 \%$ of the recovered radioactivity was present in the second hemoglobin peak, which indicated that the fetal hemoglobin fraction did not contain appreciable amounts of hemoglobin A. Yields of hemoglobin of $95-105 \%$ were consistently obtained. This method (11) offers significant advantages over other methods for separation of radioactive hemoglobins $A$ and $F(13,14)$ in that it is performed at room temperature, gives complete separation of the hemoglobins in a single procedure, and allows removal of radioactive nonheme proteins before elution of the hemoglobin fractions.

We determined hemoglobin concentrations by measuring the absorbancy at 522 or $542 \mathrm{~m} \mu$ of the carboxyhemoglobins (15).

Radioactivity determination. For determination of the specific activities of the isolated hemoglobins, the chromatographic fractions were combined and trichloroacetic acid (TCA) added to a final concentration of $10 \%$. The precipitates were collected and washed two times with $5 \%$ TCA, once with $5 \% \mathrm{TCA}$ at $90^{\circ} \mathrm{C}$ for $15 \mathrm{~min}$, once with $5 \% \mathrm{TCA}$ at room temperature, two times with absolute 


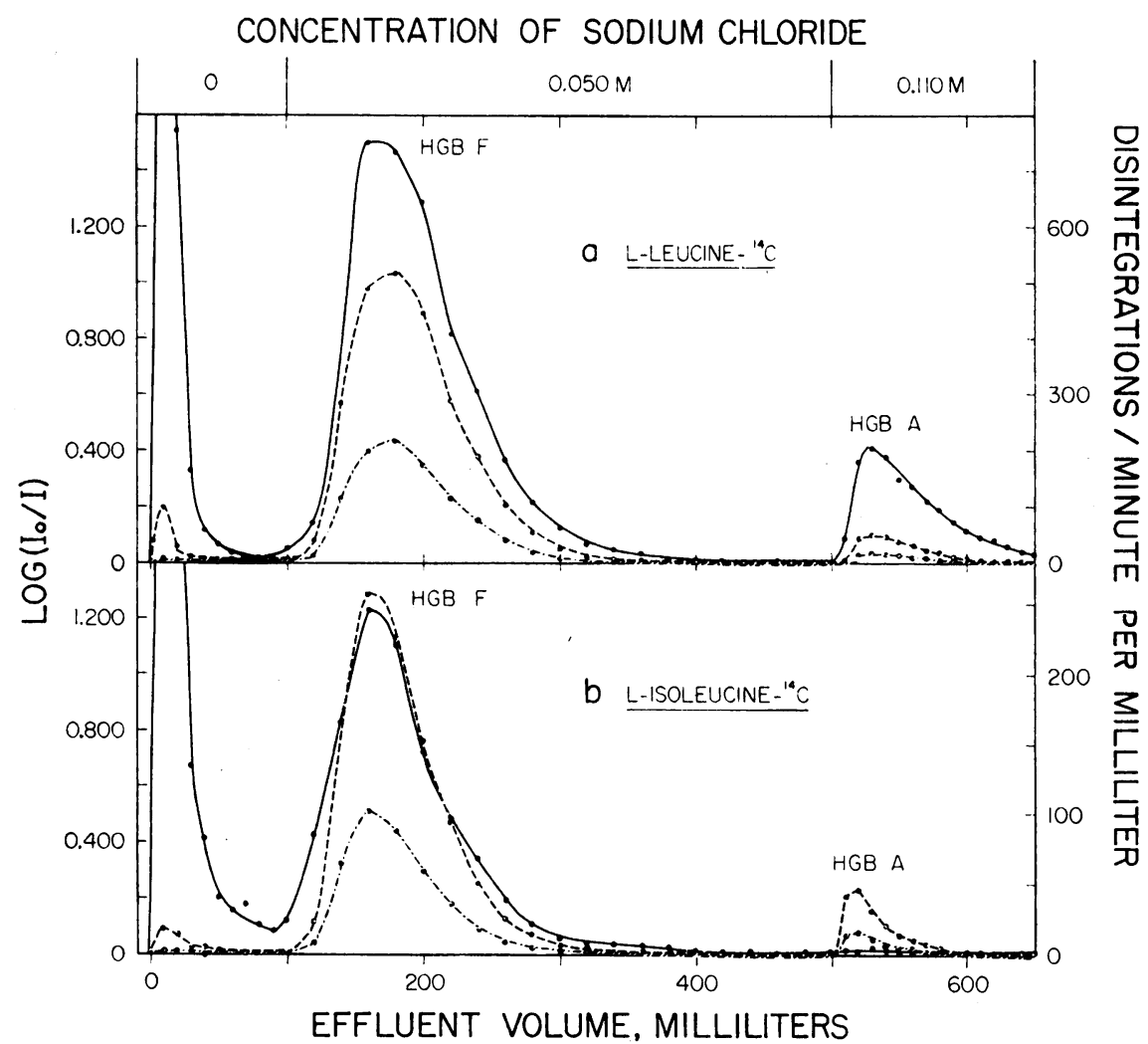

Fig. 1. Chromatographic separation of hemoglobins ( $H G B$ ) F and A. Cells from cord blood of a normal newborn infant were incubated for $2 \mathrm{hr}$ with uniformly labeled radioactive amino acids as indicated. - - - absorbancy at $280 \mathrm{~m} \mu$; - . - . absorbancy at $542 \mathrm{~m} \mu$; — radioactivity.

ethanol, two times with ethanol-ether $3: 1(\mathrm{v} / \mathrm{v})$ at $62^{\circ} \mathrm{C}$, and three times with ether. The dried precipitates were piated on tared aluminum planchets and counted in a $\mathrm{Nu}$ clear-Chicago gas flow counter with a Micromil window (16). Corrections were made for self-absorption of the samples. For counting of individual chromatographic fractions, aliquots containing less than $1 \mathrm{mg}$ of hemoglobin were precipitated with $10 \%$ TCA, heated at $90^{\circ} \mathrm{C}$ for $15 \mathrm{~min}$, then collected on Millipore filter discs (Millipore Filter Corp., Bedford, Mass.), and washed with $5 \%$ TCA. The discs were dried, then placed in scintillation counting vials containing $10 \mathrm{ml}$ of a 2,5-diphenyloxazole-

TABLE I

Incorporation of radioactive amino acids into fetal hemoglobin by erythroid cells in vitro

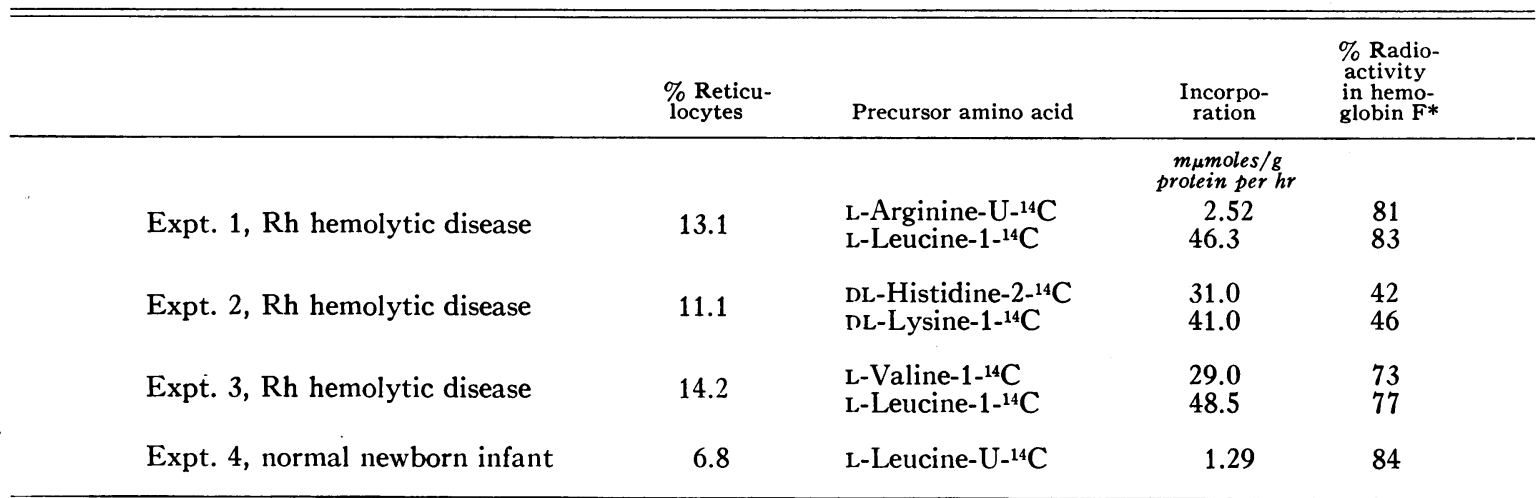

* Expressed as percentage of total radioactivity recovered in hemoglobin. 
toluene mixture, $4 \mathrm{~g} /$ liter, and counted in a Packard scintillation spectrometer (Packard Instrument Co., Inc., Downers Grove, I11.).

\section{Results}

Incorporation of amino acids into hemoglobin. The incorporation of several radioactive amino acids into hemoglobin $\mathrm{F}$ is presented in Table $\mathrm{I}$. Results of a single experiment with cells from cord blood of a normal newborn infant are also included. The radioactivity incorporated into hemoglobin $\mathrm{F}$ by cells from erythroblastotic infants comprised $42-83 \%$ of the total radioactivity recovered in hemoglobin, with a mean value of $67 \%$. These values are in the same range as those from other studies with cells from normal newborns $(7,17,18)$. The similarity in the pattern of hemoglobin synthesis by cells from infants with erythroblastosis and those from normal infants supports the suggestion (19) that the increased percentage of hemoglobin A measured in blood of erythroblastotic infants (19-21) reflects a selective destruction of cells containing fetal hemoglobin, rather than a relative increase in the synthesis of hemoglobin $\mathrm{A}$ in this disorder.<smiles>CCC(C)C(N)C(=O)O</smiles>

Fig. 2. Chemical STRUCtURES OF ISOlEUCine AND $O$-METHYLTHREONINE.

Inhibition of fetal hemoglobin synthesis by L-O, methylthreonine. The isoleucine analogue $\mathrm{L}-\mathrm{O}$ methylthreonine differs from isoleucine by an ether linkage which replaces a methylene group of the natural amino acid (Fig. 2). This analogue is a competitive inhibitor of isoleucyl-RNA synthetase, and is not incorporated into protein by mammalian cells (22).

The time course of incorporation of L-leucine-1${ }^{14} \mathrm{C}$ into hemoglobins $\mathrm{A}$ and $\mathrm{F}$ and the effect of L-O-methylthreonine are presented in Fig. 3 . The rate of synthesis of hemoglobin $F$ was effectively inhibited by the analogue, whereas the concomitant synthesis of hemoglobin A was not signifi-

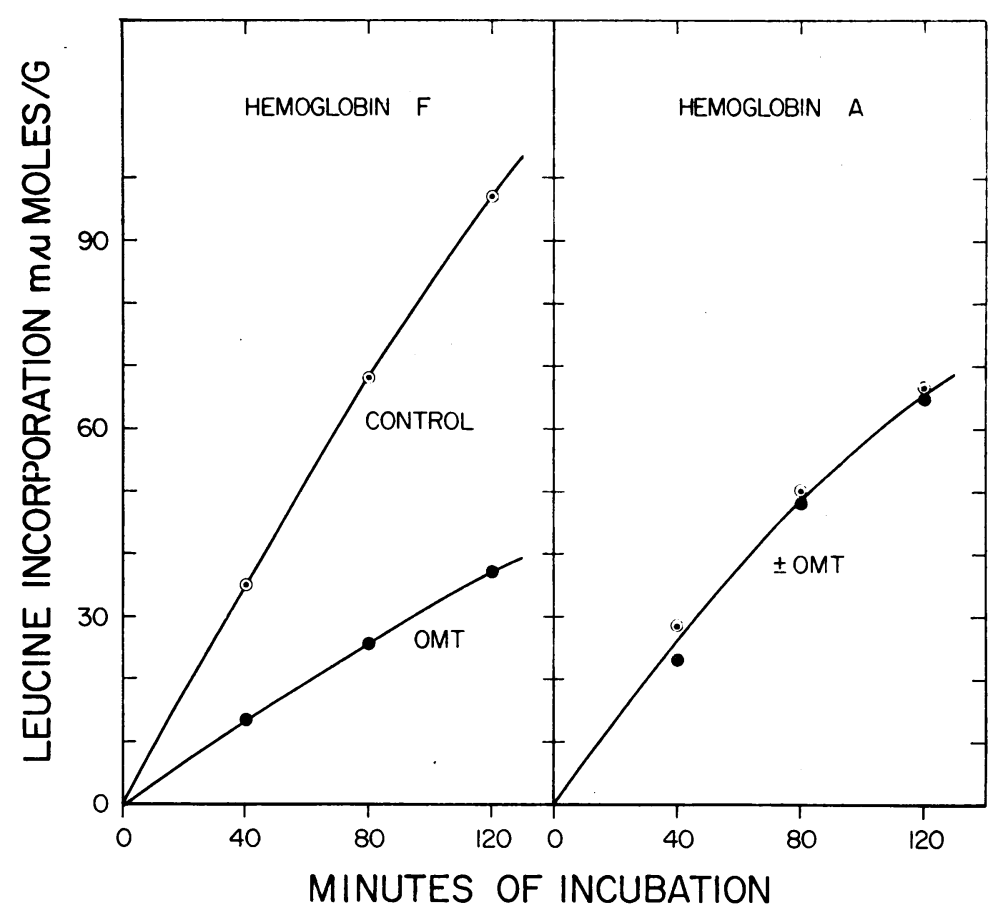

Fig. 3. Time COURSE OF INCORPORATION OF L-LEUCINE-1- ${ }^{14} \mathrm{C}$ INTO HEMOGLOBINS F AND A AND EFFECT OF L-O-METhYLThREONINE $(O M T)$. Open circles, controls; closed circles, cells incubated with $O$-methylthreonine. 
TABLE II

Inhibition of synthesis of fetal hemoglobin by L-O-methylthreonine

\begin{tabular}{|c|c|c|c|c|}
\hline \multirow[b]{2}{*}{ Precursor amino acid } & \multirow[b]{2}{*}{ Addition } & \multirow{2}{*}{$\begin{array}{c}\text { Incubation } \\
\text { time }\end{array}$} & \multicolumn{2}{|c|}{ Incorporation } \\
\hline & & & $\mathrm{Hgb} \mathrm{F}$ & $\overrightarrow{\mathrm{Hgb} \mathrm{A}}$ \\
\hline & & $\min$ & \multicolumn{2}{|c|}{ mumoles $/ \mathrm{g} \mathrm{Hgb}$} \\
\hline L-Arginine-U- ${ }^{14} \mathrm{C}$ & $\begin{array}{l}\text { None (control) } \\
\text { OMT } \\
\text { OMT + L-isoleucine }\end{array}$ & 210 & $\begin{array}{l}8.85 \\
3.86 \\
8.45\end{array}$ & $\begin{array}{l}4.65 \\
4.38 \\
4.61\end{array}$ \\
\hline L-Leucine-1-14 C & $\begin{array}{l}\text { None (control) } \\
\text { OMT } \\
\text { OMT + L-isoleucine }\end{array}$ & 210 & $\begin{array}{c}161 \\
59 \\
161^{*}\end{array}$ & $\begin{array}{l}81.0 \\
82.3 \\
60.0\end{array}$ \\
\hline DL-Histidine- $2-{ }^{14} \mathrm{C}$ & $\begin{array}{l}\text { None (control) } \\
\text { OMT } \\
\text { OMT + L-isoleucine } \\
\text { L-Isoleucine }\end{array}$ & 60 & $\begin{array}{l}31.0 \\
13.5 \\
25.0 \\
30.5\end{array}$ & $\begin{array}{l}35.9 \\
26.0 \\
29.8 \\
36.8\end{array}$ \\
\hline L-Valine- $1-{ }^{14} \mathrm{C}$ & $\begin{array}{l}\text { None (control) } \\
\text { OMT } \\
\text { OMT + L-isoleucine } \\
\text { L-Isoleucine }\end{array}$ & 120 & $\begin{array}{l}57.9 \\
25.8 \\
55.2 \ddagger \\
51.5\end{array}$ & $\begin{array}{l}43.4 \\
39.1 \\
29.3 \\
38.4\end{array}$ \\
\hline
\end{tabular}

OMT, L-O-methylthreonine; Hgb, hemoglobin.

* Because of the inhibition of incorporation into hemoglobin $\mathrm{A}$, the value for hemoglobin $\mathrm{F}$ was multiplied by $81 / 60$ for comparison with the other values.

$\ddagger$ The experimental value was multiplied by $43.4 / 29$.3.

cantly changed. A similarly selective inhibitory effect on the synthesis of hemoglobin $F$ was observed when other radioactive amino acids were used as precursors, and the addition of L-isoleucine to the incubation media prevented the inhibition (Table II). Whereas synthesis of hemoglobin A was not significantly inhibited by L-Omethylthreonine, in experiments in which radioactive L-leucine or L-valine were used as precursors the addition of $O$-methylthreonine together with isoleucine inhibited amino acid incorporation into both hemoglobins $\mathrm{F}$ and $\mathrm{A}$. For these experiments the values obtained for hemoglobin $F$ were corrected by multiplication by an appropriate factor which corrected the value for hemoglobin A to its control value. This type of inhibition did not occur when isoleucine was added without $O$-methylthreonine; an explanation for this phenomenon is not apparent, but since these amino acids are closely related chemically to isoleucine, an effect on amino acid transport into the cell may have been involved.

Distribution of hemoglobins $A$ and $F$ in reticulocytes. The reticulocytes comprise the principal cells of peripheral blood which are capable of hemoglobin synthesis (23). The blood samples used for these studies also contained small numbers of normoblasts which synthesize hemoglobin, but mature erythrocytes are inactive in this capacity
(23). The distribution of hemoglobins $\mathrm{A}$ and $\mathrm{F}$ in the reticulocytes was studied by a method described by Garby, Sjölin, and Vuille (18). We prepared reticulocyte smears after staining the cells with aqueous new methylene blue (24). The preparations were then subjected to the selective elution procedure of Betke and Kleihauer (25) for demonstration of hemoglobin F. For improved identification of the reticulocytes, the slides were counterstained with Wright's stain. Reticulocytes were classified into three groups: $(a)$ those appearing to contain only hemoglobin $\mathrm{F} ;(b)$ those appearing to be devoid of hemoglobin $F$; and $(c)$ those having intermediate amounts, which were presumed to be capable of synthesis of both hemoglobins $\mathrm{F}$ and $\mathrm{A}$. Analysis of large numbers of cells indicated that approximately $50 \%$ of reticulocytes from infants with isoimmune hemolytic disease contained intermediate amounts of hemoglobin $F$, with the remainder of the reticulocytes nearly equally divided between the other two groups. It would appear, therefore, that a significant portion of hemoglobin synthesis carried out by these reticulocytes is produced by cells capable of synthesizing both hemoglobins $F$ and $A$.

\section{Discussion}

These studies demonstrate that reticulocytes from newborn infants with isoimmune hemolytic 
disease actively incorporate radioactive amino acids into hemoglobins $\mathrm{F}$ and $\mathrm{A}$ in vitro, and that a selective inhibition of synthesis of hemoglobin $\mathrm{F}$ can be achieved by the addition of an isoleucine analogue. The isoleucine present in hemoglobin $F$ is confined to the gamma chains, which contain four residues of isoleucine per chain (26). The inhibition of synthesis of hemoglobin $\mathrm{F}$ by L- $O$-methylthreonine would therefore appear to result from a specific inhibitory effect of the analogue on gammachain production.

This experimental system may provide a useful model of human thalassemia of a gamma-chain type. The similarity of this chemical lesion to human thalassemia is clearly limited to the decreased rate of synthesis of a single chain of hemoglobin which both of them appear to manifest. The nature of the biosynthetic defect in thalassemia is not known; Itano (27) has suggested the possibility of an anomalous degenerate codon in the RNA template for the synthesis of a single hemoglobin chain. Assuming a relative deficiency of transfer-RNA species to correspond to the altered codon, such a mutation could be expected to inhibit hemoglobin synthesis because of a deficit of suitable activated amino acids at the ribosomal protein-synthesizing sites. A lesion of this type might produce an inhibition of hemoglobin synthesis similar to that seen with the present model.

The observation that the synthesis of hemoglobin A was unchanged by the inhibition of synthesis of hemoglobin F, in a cell population capable of synthesis of both of these species, suggests that these cells do not possess a cytoplasmic compensatory mechanism for increased beta-chain synthesis when gamma-chain production is suppressed. The physiological "switchover" from synthesis of hemoglobin $\mathrm{F}$ to that of hemoglobin $\mathrm{A}$ in the perinatal period would appear, therefore, not to be a consequence of an inhibition of gammachain production, at least at the ribosomal level of protein synthesis. We further conclude that the biosynthetic apparatus for the beta and gamma chains must function in an independent manner.

A common requirement for production of both hemoglobins $\mathrm{F}$ and $\mathrm{A}$ is the synthesis of alpha chains. Evidence has been presented which suggests that the release of alpha chains from ribosomes, as well as their synthesis, by reticulocytes from rabbits (6) or human adults (3), may re- quire the prior synthesis of beta chains, as part of a coordinated mechanism for balanced synthesis of the two types of complementary chains. A mechanism of this type might be at least partially responsible for the absence of appreciable accumulation of free alpha chains or subunits in red cell hemolysates in beta thalassemia (4). Fessas, Loukopoulos, and Kaltsoya (28) have recently shown, however, that erythroid cells from patients with beta thalassemia contain inclusion bodies composed largely of precipitated alpha chains, which could account for this finding. Several recent studies $(3,29,30)$, moreover, have shown an increase in the rate of alpha-chain synthesis as compared with beta-chain synthesis in reticulocytes from patients with beta thalassemia. It will be of importance to determine whether the unbalanced synthesis of the hemoglobin chains in thalassemia indicates the absence of a control mechanism in erythroid cells for the coordinated synthesis of the globin components of hemoglobin $(3,6)$ or is a specific manifestation of the biosynthetic defect in thalassemia. The selective inhibition of synthesis of gamma chains which can be achieved by the present system may be applicable for gaining further understanding of this relationship in the synthesis of the component chains of hemoglobin.

\section{Acknowledgments}

Continued support and encouragement by Dr. Irving Schulman is gratefully acknowledged. I am indebted to Dr. Marco Rabinovitz, National Cancer Institute, for a gift of L-O-methylthreonine and for helpful advice during the course of these studies. Blood samples were obtained through the cooperation of Doctors Michael Limosani, Martin Sacks, and John Boehm. Mr. Jeffrey Sklar provided valuable assistance with some of these studies. I am indebted to Doctors Irving Schulman, Marco Rabinovitz, Charles Abildgaard, and Martin Schulman for critical reading of the manuscript.

\section{References}

1. Weatherall, D. J. 1965. The Thalassaemia Syndromes. Blackwell Scientific Publications Ltd., Oxford.

2. Baglioni, C. 1963. Correlations between genetics and chemistry of human hemoglobins. In Molecular Genetics. J. H. Taylor, editor. Academic Press Inc., New York. 405.

3. Weatherall, D. J., J. B. Clegg, and M. A. Naughton. 1965. Globin synthesis in thalassaemia: An in vitro study. Nature. 208: 1061. 
4. Fessas, P., and D. Loukopoulos. 1964. Alpha-chain of human hemoglobin: Occurrence in vivo. Science. 143: 590.

5. Zuckerkandl, E. 1964. Controller-gene diseases: The operon model as applied to $\beta$-thalassemia, familial fetal hemoglobinemia and the normal switch from the production of fetal hemoglobin to that of adult hemoglobin. J. Mol. Biol. 8: 128.

6. Colombo, B., and C. Baglioni. 1966. Regulation of haemoglobin synthesis at the polysome level. $J$. Mol. Biol. 16: 51 .

7. Allen, D. W., and J. H. Jandl. 1960. Factors influencing relative rates of synthesis of adult and fetal hemoglobin in vitro. J. Clin. Invest. 39: 1107.

8. Borsook, H., E. H. Fischer, and G. Keighley. 1957. Factors affecting protein synthesis in vitro in rabbit reticulocytes. J. Biol. Chem. 229: 1059.

9. Rabinovitz, M., M. E. Olson, and D. M. Greenberg. 1959. Steric relationship between threonine and isoleucine as indicated by an antimetabolite study. J. Am. Chem. Soc. 77: 3109.

10. Lingrel, J. B., and H. Borsook. - 1963. A comparison of amino acid incorporation into the hemoglobin and ribosomes of marrow erythroid cells and circulating reticulocytes of severely anemic rabbits. Biochemistry. 2: 309.

11. Zade-Oppen, A. M. M. 1963. Separation of hemoglobin $\mathrm{A}$ and $\mathrm{F}$ by cation exchange dextran gels. Scand. J. Clin. Lab. Invest. 15 : 491.

12. Stein, W. H., H. G. Kunkel, R. D. Cole, D. H. Spackman, and S. Moore. 1957. Observations on the amino acid composition of human hemoglobins. Biochim. Biophys. Acta. 24: 640.

13. Allen, D. W., W. A. Schroeder, and J. Balog. 1958. Observations on the chromatographic heterogeneity of normal adult and fetal human hemoglobin: A study of the effects of crystallization and chromatography on the heterogeneity and isoleucine content. J. Am. Chem. Soc. 80: 1628.

14. Huisman, T. H. J., E. A. Martis, and A. Dozy. 1958. Chromatography of hemoglobin types on carboxymethylcellulose. J. Lab. Clin. Med. 52: 312.

15. Jones, R. T., and W. A. Schroeder. 1963. Chromatography of human hemoglobin. Factors influencing chromatography and differentiation of similar hemoglobins. J. Chromatog. 10: 421.

16. Kamen, M. D. 1957. Isotopic Tracers in Biology. Academic Press Inc., New York. 3rd edition. 70.

17. Burka, E. R., and P. A. Marks. 1964. Control of haemoglobin $A$ and $F$ synthesis: Haemoglobin formation in foetal and adult erythroid cells. Nature. 204 : 659.

18. Garby, L., S. Sjölin, and J. Vuille. 1962. Studies on erythro-kinetics in infancy. II. The relative rate of synthesis of haemoglobin $\mathrm{F}$ and haemoglobin A during the first months of life. Acta Paediat. $51: 245$.

19. Brody, S., and L. Engström. 1960. Foetal and adult haemoglobin in newborn infants with erythroblastosis foetalis. Acta Paediat. 49: 868.

20. Schulman, I., and C. H. Smith. 1954. Fetal and adult hemoglobins in hemolytic disease of the newborn. Am. J. Diseases Children. 87: 167.

21. Oppé, T. E., and I. D. Fraser. 1961. Foetal haemoglobin in haemolytic disease of the newborn. Arch. Disease Childhood. 36 : 507.

22. Smulson, M. E., and M. Rabinovitz. 1966. Mechanism of inhibition of protein synthesis in Sarcoma 37 ascites cells by the isoleucine antagonist, O-methylthreonine. Federation Proc. 25: 783. (Abstr.)

23. Holloway, B. W., and S. H. Ripley. 1952. Nucleic acid content of reticulocytes and its relation to uptake of radioactive leucine in vitro. J. Biol. Chem. 196: 695.

24. Brecher, G. 1949. New methylene blue as a reticulocyte stain. Am. J. Clin. Pathol. 19: 895.

25. Betke, K., and E. Kleihauer. 1958. Fetaler und bleibender Blutfarbstoff in Erythrozyten und Erythroblasten von menschlichen Feten und Neugeborenen. Blut. $4: 241$.

26. Schroeder, W. A., J. R. Shelton, J. B. Shelton, J. Cormick, and R. T. Jones. 1963. The amino acid sequence of the $\gamma$ chain of human fetal hemoglobin. Biochemistry. 2 : 992.

27. Itano, H. A. 1965. The synthesis and structure of normal and abnormal hemoglobins. In Abnormal Haemoglobins in Africa. J. H. P. Jonxis, editor. Blackwell Scientific Publications Ltd., Oxford. 3.

28. Fessas, P., D. Loukopoulos, and A. Kaltsoya. 1966. Peptide analysis of the inclusions of erythroid cells in $\beta$-thalassemia. Biochem. Biophys. Acta $124: 430$.

29. Bank, A., and P. A. Marks. 1966. Excess $\alpha$ chain synthesis relative to $\beta$ chain synthesis in thalassaemia major and minor. Nature. 212: 1198.

30. Bargellesi, A., S. Pontremoli, and F. Conconi. 1967. Absence of $\beta$ globin synthesis and excess of $\alpha$ globin synthesis in homozygous $\beta$-thalassemia. European J. Biochem. 1: 73. 